\title{
The landscape of bilateral adrenal incidentalomas associated with subclinical hypercortisolism
}

\author{
Guido Di Dalmazi (i) ${ }^{1}$
}

Received: 16 February 2016 / Accepted: 26 May 2016 / Published online: 1 July 2016

(C) Springer Science+Business Media New York 2016

Since the first report of a "subclinical" Cushing's syndrome dated back to the early 1970s [1], a great deal of effort has been put to understand the molecular pathogenesis and the clinical correlates of this condition. Despite the exponential number of publications over the last years, it is still difficult to draw definitive conclusions on the clinical impact of incidentally diagnosed hypercortisolism, not associated with a clear Cushing's phenotype. As every physician involved in the management of adrenal diseases knows, the main source of uncertainty resides in the definition of this pathological condition, which generates difficulties in achieving comparable results among different studies, and the lack of well-designed prospective studies covering a long time span, leading to difficulties in estimating the prevalence of cortisol-associated comorbidities and longterm consequences. However, keeping in mind those limitations, evidence from long-term retrospective studies has indirectly shown that a mild, but sustained, cortisol hypersecretion can be related to an increased risk of cardiovascular and metabolic correlates, which seems to be related to the cortisol secretion, as well as to the progressive secreting pattern over time [2-4].

Most of the studies on long-term consequences are focused on unilateral adrenocortical tumors, which represent the most frequent entity in radiological series. Lately, an increasing number of studies have been focused on the analysis of hormonal and clinical characteristics of bilateral incidentalomas, raising attention to the difficulties of the

Guido Di Dalmazi

Guido.Di_Dalmazi@med.uni-muenchen.de gdd1982@gmail.com

1 Medizinische Klinik und Poliklinik IV, Klinikum der Universität München, Ziemssenstr. 1, 80336 Munich, Germany clinical management of those tumors. The recent advances in the biology of cortisol-secreting tumors have also shed light on the molecular events underlying bilateral adrenocortical tumors, which can be very different from their unilateral counterpart and involve novel pathogenic pathways and previously unknown regulatory mechanisms. The discovery of mutations in the ARMC5 gene in a substantial number of patients with bilateral adrenal hyperplasia and hypercortisolism [5] has broadened the view on the molecular mechanisms underlying adrenocortical hyperplasia, adding an important piece of knowledge to our understanding of tumorigenesis and hormonal hypersecretion in adrenal tumors. Research on aberrant receptors and paracrine regulation of cortisol secretion has provided evidence that the pathophysiology of bilateral masses can be extremely complex. According to the results of in vivo and in vitro studies, the presence of illegitimate receptors is indeed a frequent event among patients with bilateral adrenocortical hyperplasia, with a prevalence that rises up to $87 \%$ [6]. Moreover, after the first pioneering studies [7], the discovery of intra-adrenal adrenocorticotropic hormone (ACTH) production in a substantial number of patients with hypercortisolism [8] has completely changed the knowledge on the feedback mechanisms involved in adrenal steroidogenesis.

The review published by Paschou and colleagues [9] was aimed to investigate the relationship between morphological characteristics of the adrenal glands and the secretory pattern, with focus on incidentally discovered adrenocortical tumors and subclinical hypercortisolism. Based on the data provided by six studies published between 2011 and 2015, the main finding of the review is that the overall prevalence of subclinical hypercortisolism is increased in bilateral adrenal incidentalomas vs. unilateral adenomas. Surprisingly, the 
prevalence of comorbidities potentially related to mild cortisol excess was not different between unilateral and bilateral adrenocortical masses, when analyzed independently of the secreting pattern. However, it must be pointed out that the data on comorbidities are not representative of the whole cohort, since they are presented only in half of the total group of patients considered in the meta-analysis. Despite this limitation, the data provided on the prevalence of comorbidities are interesting and may find their explanation in the regulation of cortisol chronobiology, which seems to be different in bilateral vs. unilateral adrenocortical incidentalomas [10], due to the different molecular background, and is likely to have some impact on the cortisol-related comorbidities and their progression.

The detection of bilateral adrenocortical tumors and the increasing prevalence of subclinical hypercortisolism in this pathological condition represent a major challenge for physicians, due to difficulties in diagnosis and follow-up. Indeed, no radiological guidelines have been provided yet for bilateral incidentalomas. The cutoff of $10 \mathrm{~mm}$, frequently adopted for the definition of adrenal incidentalomas, is arbitrary and better directions for lesions below this cutoff would help to characterize patients with micronodules or adrenal gland enlargement. Moreover, the current options for the management of subclinical hypercortisolism should be reviewed in the light of a tailored approach. In fact, considering that the reported rate of malignant transformation of incidentally discovered adrenocortical masses is extremely low [11], it is questionable whether a radiological follow-up is really necessary in those patients, provided that an initial evaluation has been performed properly. Given the linear relationship between cortisol secretion and adrenocortical mass volume in subclinical hypercortisolism [12], it is conceivable that a radiological evaluation may be repeated in case of a significant modification of the hormonal profile, in light of a surgical approach. The possibility to identify the lateralization of cortisol secretion, if any, is a feasible strategy that can be applied to guide the choice of the surgical procedure for bilateral adrenocortical incidentalomas, with significant advantages for the patient. To this scope, adrenal vein sampling has been successfully performed to identify the source of cortisol secretion in patients with bilateral adrenal incidentalomas [13], even if this method has not gained popularity so far. More research is definitely needed to assess the risk/benefit ratio and investigate the usefulness of this invasive procedure. Recent evidence highlighted that adrenal scintigraphy with 131I-6 $\beta$-iodomethylnorcholesterol may be another useful option in identifying the lateralization of cortisol excess [14]. Finally, pharmacological treatment targeting specific pathways according to the underlying alteration is already an encouraging perspective, as an alternative to the surgical approach, for treatment of bilateral diseases in case of illegitimate receptors [15], even if more research is definitely required in this field.

In conclusion, the review by Paschou and colleagues [9] draws attention to the topic of bilateral adrenocortical tumors, which has been the subject of exciting discoveries during the very last years. More research is now needed to understand the clinical significance of subclinical hypercortisolism in bilateral adrenal diseases, in order to plan reliable follow-up strategies for this non-negligible number of patients.

\section{Compliance with ethical standards}

Conflict of interest The author declares that he has no conflict of interest.

\section{References}

1. W.H. Beierwaltes, M.F. Sturman, U. Ryo, R.D. Ice, Imaging functional nodules of the adrenal glands with 131-I-19iodocholesterol. J. Nucl. Med. 15, 246-251 (1974)

2. G. Di Dalmazi, V. Vicennati, S. Garelli, E. Casadio, E. Rinaldi, E. Giampalma, C. Mosconi, R. Golfieri, A. Paccapelo, U. Pagotto, R. Pasquali, Cardiovascular events and mortality in patients with adrenal incidentalomas that are either non-secreting or associated with intermediate phenotype or subclinical Cushing's syndrome: a 15-year retrospective study. Lancet Diabetes Endocrinol. 2, 396-405 (2014)

3. M. Debono, M. Bradburn, M. Bull, B. Harrison, R.J. Ross, J. Newell-Price, Cortisol as a marker for increased mortality in patients with incidental adrenocortical adenomas. J. Clin. Endocrinol. Metab. 99, 4462-4470 (2014)

4. V. Morelli, G. Reimondo, R. Giordano, S. Della Casa, C. Policola, S. Palmieri, A.S. Salcuni, A. Dolci, M. Mendola, M. Arosio, B. Ambrosi, A. Scillitani, E. Ghigo, P. Beck-Peccoz, M. Terzolo, I. Chiodini, Long-term follow-up in adrenal incidentalomas: an Italian multicenter study. J. Clin. Endocrinol. Metab. 99, 827-834 (2014)

5. G. Assié, R. Libé, S. Espiard, M. Rizk-Rabin, A. Guimier, W. Luscap, O. Barreau, L. Lefèvre, M. Sibony, L. Guignat, S. Rodriguez, K. Perlemoine, F. René-Corail, F. Letourneur, B. Trabulsi, A. Poussier, N. Chabbert-Buffet, F. Borson-Chazot, L. Groussin, X. Bertagna, C.A. Stratakis, B. Ragazzon, J. Bertherat, ARMC5 mutations in macronodular adrenal hyperplasia with Cushing's syndrome. N. Engl. J. Med. 369, 2105-2114 (2013)

6. R. Libé, J. Coste, L. Guignat, F. Tissier, H. Lefebvre, G. Barrande, C. Ajzenberg, I. Tauveron, E. Clauser, B. Dousset, X. Bertagna, J. Bertherat, L. Groussin, Aberrant cortisol regulations in bilateral macronodular adrenal hyperplasia: a frequent finding in a prospective study of 32 patients with overt or subclinical Cushing's syndrome. Eur. J. Endocrinol. 163, 129-138 (2010)

7. H. Lefebvre, C. Duparc, N. Chartrel, S. Jegou, A. Pellerin, A. Laquerriere, R. Ivell, H. Vaudry, J.M. Kuhn, Intraadrenal adrenocorticotropin production in a case of bilateral macronodular adrenal hyperplasia causing Cushing's syndrome. J. Clin. Endocrinol. Metab. 88, 3035-3042 (2003)

8. E. Louiset, C. Duparc, J. Young, S. Renouf, M. Tetsi Nomigni, I. Boutelet, R. Libé, Z. Bram, L. Groussin, P. Caron, A. Tabarin, F. Grunenberger, S. Christin-Maitre, X. Bertagna, J.M. Kuhn, Y. Anouar, J. Bertherat, H. Lefebvre, Intraadrenal corticotropin in bilateral macronodular adrenal hyperplasia. N. Engl. J. Med. 369. 2115-2125 (2013) 
9. S.A. Paschou, E. Kandaraki, F. Dimitropoulou, D.G. Goulis, A. Vryonidou, Subclinical Cushing's syndrome in patients with bilateral compared to unilateral adrenal incidentalomas: a systematic review and meta-analysis. Endocrine. doi: 10.1007/ s12020-015-0776-6 (2015)

10. M.O. van Aken, A.M. Pereira, S.W. van Thiel, G. van den Berg, M. Frölich, J.D. Veldhuis, J.A. Romijn, F. Roelfsema, Irregular and frequent cortisol secretory episodes with preserved diurnal rhythmicity in primary adrenal Cushing's syndrome. J. Clin. Endocrinol. Metab. 90, 1570-1577 (2005)

11. T.J. Cawood, P.J. Hunt, D. O'Shea, D. Cole, S. Soule, Recommended evaluation of adrenal incidentalomas is costly, has high false-positive rates and confers a risk of fatal cancer that is similar to the risk of the adrenal lesion becoming malignant; time for a rethink? Eur. J. Endocrinol. 161, 513-527 (2009)

12. I. Perogamvros, D.A. Vassiliadi, O. Karapanou, E. Botoula, M. Tzanela, S. Tsagarakis, Biochemical and clinical benefits of unilateral adrenalectomy in patients with subclinical hypercortisolism and bilateral adrenal incidentalomas. Eur. J. Endocrinol. 173, 719-725 (2015)

13. W.F. Young Jr, H. du Plessis, G.B. Thompson, C.S. Grant, D.R. Farley, M.L. Richards, D. Erickson, A. Vella, A.W. Stanson, J.A. Carney, C.F. Abboud, P.C. Carpenter, The clinical conundrum of corticotropin-independent autonomous cortisol secretion in patients with bilateral adrenal masses. World J. Surg. 32, 856-862 (2008)

14. L. Papierska, J. Ćwikła, M. Rabijewski, P. Glinicki, M. Otto, A. Kasperlik-Załuska, Adrenal (131)I-6 $\beta$-iodomethylnorcholesterol scintigraphy in choosing the side for adrenalectomy in bilateral adrenal tumors with subclinical hypercortisolemia. Abdom. Imaging. 40, 2453-2460 (2015)

15. N. El Ghorayeb, I. Bourdeau, A. Lacroix, Multiple aberrant hormone receptors in Cushing's syndrome. Eur. J. Endocrinol. 173, M45-M60 (2015) 